INVESTIGACIÓN/RESEARCH

\title{
EL “CIUDADANO”, TELESPECTADOR EN EL DISCURSO MEDIÁTICO CHILENO
}

Lorena Antezana Barrios1: Universidad de Chile. Chile

lorena.antezana@gmail.com

\section{RESUMEN}

La democracia condujo a un alargamiento del espacio público donde los medios asumen un rol creciente y donde la televisión -y específicamente el noticiero televisivocumplen una función importante al establecer un puente entre el público y las autoridades. Es decir, el noticiero televisivo cumple una función de "bisagra relacional" articulando estas dos grandes instancias, pero en una plataforma que no es neutra, al presentar las distintas voces de los actores implicados en los acontecimientos organizándolas de acuerdo a un tipo de lógica argumentativa que responde a la esencia distintiva de cada canal. El espacio del noticiero se constituiría por tanto, en un lugar de debate de intereses públicos y privados y en el lugar de constitución de una opinión que presupone un tipo de ciudadano particular, por tanto ¿A qué tipo de ciudadano apela la entidad televisiva?

PALABRAS CLAVE: Noticiero televisivo - Ciudadanía - Democracia - Participación Espacio público

\section{THE "CITIZEN", VIEWER SPEECH IN CHILEAN MEDIA}

\begin{abstract}
Democracy led to an expansion of public space where the media plays a growing role and where television, -and specifically television news- fulfills an important function by establishing a bridge between the public and government officials. Television news programs serve as a "relationship hinge" linking these two major groups on a neutral platform. This platform presents the different voices of stakeholders involved in

\footnotetext{
${ }^{1}$ Autor correspondiente:

Lorena Antezana-Barrios: Profesora Doctora del Instituto de la Comunicación e Imagen en la Universidad de Chile, Chile

Correo: lorena.antezana@gmail.com
} 
events, organizing them according to a type of argumentative logical which is determined by the distinctive essence of each channel. The news program, therefore, becomes a place for debating public and private interests and developing an opinion which presupposes a particular type of citizen. What type of citizen, then, are television news programs aimed at?

KEY WORDS: Television news - Citizens - Democracy - Participation - Public space

\section{INTRODUCCIÓN}

Con la incorporación de las nuevas tecnologías, la forma tradicional de organización social que se centraba en espacios físicos de encuentro concebidos como los "[...] sitios donde se creaban normas -para permitir que se hiciera justicia- y se las aplicaba de manera horizontal, con lo cual los conversadores se constituían en una comunidad, apartada e integrada por los criterios de evaluación compartidos" (Bauman, 2008, p. 37) se disuelven. Los límites espacio-temporales cambiaron producto de los nuevos dispositivos tecnológicos y de la consolidación de la democracia como forma de organización social.

En este contexto, los medios de comunicación son la principal institución que dota de sentido y permite que los telespectadores (heterogéneos, diversos, anónimos) puedan adquirir una idea de comunidad, de mundo compartido en el que se hacen visibles problemáticas que son comunes ya que "la información es un modo de dar forma a las relaciones sociales" (Lechner, 2005, p. 251).

Los medios por tanto, y en particular la televisión, se convierten en lugares clave de recreación del espacio público y de mediación entre los ciudadanos y las autoridades, fundamentalmente el noticiero televisivo que es el que en mayor medida brinda las pautas que los "nuevos ciudadanos" necesitan para operar en el escenario actual.

\section{METODOLOGÍA}

De acuerdo a nuestras investigaciones ${ }^{2}$, el noticiero televisivo chileno permitiría: (a) la construcción de un orden social y; (b) la construcción de un "nosotros" que, en su conjunto, garantizan el funcionamiento de un modelo de desarrollo económico capitalista instaurado durante el régimen dictatorial y consolidado durante la transición a la democracia (Antezana, 2008 y 2010).

En esta doble tarea de normalizar el comportamiento social y legitimar el modelo de desarrollo económico adoptado se opera una paradoja pues, por un lado se promueve

\footnotetext{
${ }^{2}$ Estrategias de proximidad del noticiero televisivo chilenos para vincularse con su público. Tesis para obtener el Grado de Doctor en Información y Comunicación, Universidad Católica de Lovaina. 2008. (2) El noticiero televisivo chileno: bisagra relacional entre Estado y Clases Sociales en el espacio democrático, Beca de Investigación CLACSO- ASDI 2008 - 2009.
} 
la creación de un imaginario común, de una identidad colectiva basada en la consolidación de un "nosotros" y por el otro se estimula la responsabilidad individual, basada en la productividad, la competencia y el consumo.

El noticiero televisivo establecería un puente entre el público (telespectador) y las autoridades, es decir estaría cumpliendo una función de "bisagra relacional", articulando estas dos grandes instancias pero, en una plataforma que no es neutra, que presenta las distintas voces de los actores implicados en los acontecimientos organizándolas de acuerdo a un tipo de lógica argumentativa que responde a la esencia distintiva de cada canal. El espacio del noticiero se constituiría por tanto, en un espacio de debate de intereses públicos y privados y en el lugar de constitución de una opinión que presupone un tipo de ciudadano particular, por tanto ¿Qué tipo de "ciudadano" prefigura cada canal?

Responder a esta pregunta en nuestro caso, requiere analizar la relación que propone cada canal con su público objetivo, a partir del tipo de enunciación desplegada, la que se vincula con la posición interlocutiva que la instancia televisiva utiliza. A partir del análisis de esta enunciación en la puesta en escena del noticiero, analizada en el contexto de las dos investigaciones realizadas, intentaremos definir este complejo vínculo.

Los noticieros considerados en ambas investigaciones corresponden a los de cobertura nacional que presentan mayor nivel de audiencia durante el periodo de estudio, del año 2006 al 2009. En 2010 con la puesta en marcha de los canales 24 horas y la elección de Sebastián Piñera como presidente de la República los énfasis de cada uno de estos canales se modifican.

El presente artículo se organiza en cinco partes. La primera precisa lo que se entiende como espacio público mediático en este contexto de análisis; la segunda presenta, a grandes rasgos, las características de cada uno de los canales considerados, mientras que la tercera desarrolla lo que entendemos por enunciación y la forma en que ésta opera en cada canal. Los dos últimos apartados dan cuenta del "lugar" que cada canal le otorga al telespectador y el tipo de vínculo relacional que proponen. Aquí se responde la pregunta inicial formulada describiendo al "ciudadano" al que cada entidad televisiva alude.

La mejor herramienta adecuada para nuestra investigación, por tanto, será la analítica textual de los programas que conforman la parrilla chilena. A partir de esa enumeración, se han seleccionado, por diferencial semántico, las palabras que el espectador recibe que son las más significativas para nuestro estudio de manera que se puedan crear datos de análisis estadístico sobre contenidos vehiculados a través de los principales medios de comunicación de masas chilenos. Es decir, se enjuiciará el valor de los enunciadores a partir de su capacidad para convertirse en guías de opinión. 


\section{ANÁLISIS Y DISCUSIÓN}

\subsection{El espacio público de referencia}

Pensar en un "ciudadano", entendido también como un telespectador en este contexto de investigación, implica situarlo en un determinado marco que vincula al individuo con un espacio público específico. Habermas llamará espacio público (Haber, 2001, p. 33), al lugar donde las interpretaciones y las aspiraciones en cuestión se manifiestan y adquieren consistencia a los ojos de cada uno, se interpenetran, entran en sinergia o en conflicto. Desde un punto de vista normativo, el solo concepto de "opinión pública" es aquel que designa el resultado de estos procesos. El espacio público juega, al principio una función cognitiva: las interpretaciones y las aspiraciones se expresan y se cristalizan bajo la forma de corrientes de ideas; la posición asumida y las proposiciones son difusiones que hacen que los participantes quieran situarse en algún nivel.

El espacio público de discusión se constituiría en la medida en que la figura tradicional de comunidad se detiene. Supone y trae consigo la disolución de lazos comunitarios (de simplicidad, intimidad, familiaridad, convivencia) y con ello la pérdida de las evidencias (certitudes, normas, valores) tradicionalmente compartidos (Prado, 1992:, p. 75). Además, también han cambiado las escalas:

de la operatividad instrumental del trabajo humano [...] experimentando una ampliación que ha hecho pasar a la actividad humana a un orden de medida superior $\mathrm{y}$, de esta manera, a un horizonte de posibilidades de dar y recibir formas desconocido durante milenios de historia (Echeverría, 2000, p. 145).

Entonces, por un lado, el espacio público se puede entender como un medio privilegiado para la formación de una identidad colectiva mediante la apropiación de la historia, y por otra parte este nuevo espacio público se relaciona con la escenificación de episodios hasta hace poco relativamente privados de la intimidad profesional, familiar y conyugal (Ferry, 1989, p. 20).

Charaudeau se refiere a la naturaleza del espacio público como un "discurso circulante", el que vendría a ser "una suma empírica de enunciados definitorios sobre lo que son los seres, las acciones, los acontecimientos, sus características, sus comportamientos y los juicios que se adhieren a él" (Charaudeau, 2005, p. 97).

Sumida a estos procesos, la información no puede ser un producto neutro. Es un artefacto cultural, una seguidilla de mensajes fabricados socialmente y que vehiculan un buen número de las ideas dominantes de nuestra sociedad, fragmentando la realidad e invalidando toda visión social sistémica, el discurso de la información aparece como una forma indirecta pero efectiva de "condicionamiento social" (Soulages, 1999, p. 31). 
Los medios en virtud de su función de cajas de resonancia, sirven entonces como amplificadores de los movimientos de opinión pública y facilitan la visibilidad de los líderes, a la vez que les ofrecen la posibilidad de expresarse; también contribuyen a conferirles cierta legitimidad. Los medios, en realidad, son "la otra cara" de la opinión pública, la que no tiene expresión legítima u oficial y que si embargo es capaz de desempeñar un gran papel (Wolton, 1989, p. 191).

La democracia, por tanto, requiere un espacio público en el que sean debatidos contradictoriamente los grandes problemas del momento (Wolton, 1992, p. 95). Este espacio simbólico inseparable del principio de "publicidad" y de "secularización" es una de las condiciones estructurales del funcionamiento de la misma. Este "nuevo espacio público" es el marco "mediático" gracias al cual el dispositivo institucional y tecnológico propio de las sociedades postindustriales es capaz de presentar a un "público" los múltiples aspectos de la vida social (Ferry, 1989, p. 19). El público del que se trata no está limitado en absoluto al cuerpo electoral de una nación, se trata más bien de todos los que son capaces de percibir y comprender los mensajes difundidos en el mundo. El público es, virtualmente, toda la humanidad y de un modo correlativo, el "espacio público" es el medio en el cual la humanidad se entrega a sí misma como espectáculo. En este sentido entendemos como "público" al telespectador, es decir al que accede a la plataforma informativa propuesta por el noticiero televisivo.

Las personas, consumidores, ciudadanos, telespectadores en general se dan cita frente a sus televisores, es momento de una pausa, es momento de entrar en contacto con lo que ocurre a nuestro alrededor, momento de aprendizaje, de recreación, en fin... momentos distintos para públicos variados, reales (no los presupuestados por los canales) y ese presentador que mira a los ojos ${ }^{3}$ se dirige a la mayor cantidad posible, establece un vínculo y una relación con cada uno, para tratar de atraparlos, capturarlos, seducirlos y el telespectador, al aceptar la propuesta informativa, acepta también participar de la comunidad desde el lugar que el canal le asigna. Acepta por tanto un tipo de vínculo que, en gran medida, lo define no sólo como telespectador sino que también como ciudadano.

\subsection{La estructura informativa}

La característica estructural de los noticieros televisivos más relevante para comprender el análisis propuesto, se relaciona con el tipo de propiedad de los canales televisivos considerados, los que detallamos brevemente: Televisión Nacional de Chile (TVN), ligada en su constitución al Estado, con un Directorio nombrado por el (la) Presidente, con funciones ligadas al servicio público pero cuyo financiamiento es de naturaleza privada y su estatuto organizacional es autónomo; Canal 13 (UC13), pertenece a la Universidad Católica de Chile pero también opera como empresa privada aunque se ajusta a ciertos lineamientos morales e ideológicos dictados por la

3 Siguiendo a Verón, Eliseo (1981 - 1982) Il est là, je le vois, il me parle, en Communications $n^{\circ} 38$. Paris. Ed. Du Seuil. 
Iglesia Católica4; Megavisión (MEGA), el canal privado más antiguo (a principios de los 90), que es una corporación de derecho privada cuyo propietario mayoritario es el Grupo Claro, grupo de empresarios chilenos que cuenta con otros de medios de comunicación, radios y diarios además de intereses portuarios e inmobiliarios (Sunkel, et al, 2001).

En este marco, si bien los tres canales considerados tienen en su constitución orígenes y propietarios distintos, todos funcionan bajo la lógica de la competencia de mercado, por lo cual la venta de espacios publicitarios es primordial para su subsistencia.

No existen notorias diferencias en la forma de organizar estructuralmente las diferentes temáticas que se presentan en el noticiero. Es así como los canales considerados dedican generalmente el primer bloque informativo a las noticias de índole policial, el bloque central a las notas propias (Reportajes, Crónicas, etc.) que se centran en temáticas relacionadas con Sociedad e Informaciones Generales y Economía y Social, cerrando las transmisiones con el bloque Deportivo.

Otra característica común de la ubicación del noticiero en la parrilla programática es que los programas que lo anteceden son del género ficcional (teleseries, series o películas) y los programas que los preceden en su mayoría son variados. Es importante destacar el programa que antecede al noticiero pues, una de las estrategias para captar audiencias de los noticieros es retener al público que ya se ha captado en el programa anterior y que permanece en sintonía durante el primer tercio del noticiero.

El segundo bloque del noticiero captura al público fiel y regular, es decir, los telespectadores vuelven al noticiero que tradicionalmente consumen que, en la gran mayoría de los casos, es el que veían en su familia, el que se veía con los padres y el que, muchas veces seguirán viendo los hijos. Quizás la dimensión ritual que mirar el noticiero tenía antaño se ha ido perdiendo con el tiempo y que la oferta informativa on line ha ido modificando los patrones de consumo informativo habituales; pero esto es más notorio en las nuevas generaciones y en estratos socio económicos más altos pues los noticieros de la televisión abierta siguen contando con una alta audiencia. En este bloque, cada canal despliega, en largos reportajes o crónicas, los temas que considera van a interesar a sus audiencias (público ideal) y éstos están relacionados fundamentalmente con la sección de Sociedad e Informaciones Generales. El año 2009 se presenta una diferencia interesante y es que se incorporan las notas de Economía y Social, siendo éste un segmento que comparativamente presenta un crecimiento en relación a los años anteriores.

El tercer bloque desarrolla una sección particular, en muchos casos destacada, que es la deportiva. La fuga de audiencias vuelve a producirse esta vez buscando la especialización, los rostros y comentaristas más polémicos, la transmisión de los goles

\footnotetext{
${ }^{4}$ Recientemente gran parte de sus acciones fueron compradas por grupo Luksic (ligado a la Democracia Cristiana).
} 
de algún partido. Más que información los telespectadores buscan la repetición, el análisis, el entretenimiento factores que ha sabido cultivar esta sección (Arcos, 2010).

\subsection{La "enunciación" del noticiero}

Los profesionales del noticiario (presentadores ancla, periodistas, reporteros, camarógrafos, sonidistas, etc.) que articulan, en sentido propio y figurado, los discursos múltiples que constituyen el texto del noticiero según modalidades extremadamente variables y que construyen la realidad mediática propuesta a los telespectadores, son los autores del texto televisivo (Coulomb-Gully, 2001: 19-20), pero este relato es fundamentalmente polifónico.

Por tanto, analizar en el relato informativo el aparato de su enunciación, es en principio identificar quien habla en ese texto. En un noticiero televisivo existirían cuatro tipos de instancias de enunciación (Charaudeau, 2005), la primera de ellas es la de los profesionales del medio: presentadores ancla y periodistas, las restantes tres son las de experto, testigo y actor corporativo, entendiendo como experto a aquel que habla desde un saber; por testigo a aquel que habla desde sí mismo y por actor corporativo $^{5}$ al que habla en representación de otra entidad, en representación de otro.

Otro punto importante de considerar a la hora de analizar el tipo de noticias y la enunciación de las mismas es considerar la calidad informativa, la que se mide, entre otras cosas, por la utilización de las fuentes. Los medios más rigurosos exigen contar con al menos tres para respaldar la información que se entrega. "Quién dice qué y dónde, no es un dato menor. Quienes acceden al espacio de lo simbólico - a través de los relatos comunicacionales- tienen acceso a un espacio de poder, de habla" (Lagos, 2009, p. 3).

En los noticieros chilenos la categoría de experto es la menos utilizada lo que reduce considerablemente el tipo de fuentes que respaldan una información, y por tanto dejan al periodista construir una versión propia de los acontecimientos. El saber experto es más bien neutro pues presenta y explica los acontecimientos desde un punto de vista racional y objetivo y en general refuerza y avala alguna aseveración realizada por los profesionales del medio (periodistas). En la actualidad pareciera ser más llamativo presentar una noticia desde la emoción (testigos) o desde la acusación, denuncia o explicación (actores corporativos). Es decir primaría en los canales el principio de captación (seducción del telespectador) por sobre el de información.

\footnotetext{
${ }^{5}$ Charaudeau utiliza la denominación "Actor social" para referirse a este enunciador. Sin embargo, hemos optado por modificar este concepto pues en nuestro contexto, un actor social tiene una acepción distinta a la que este autor propone.
} 


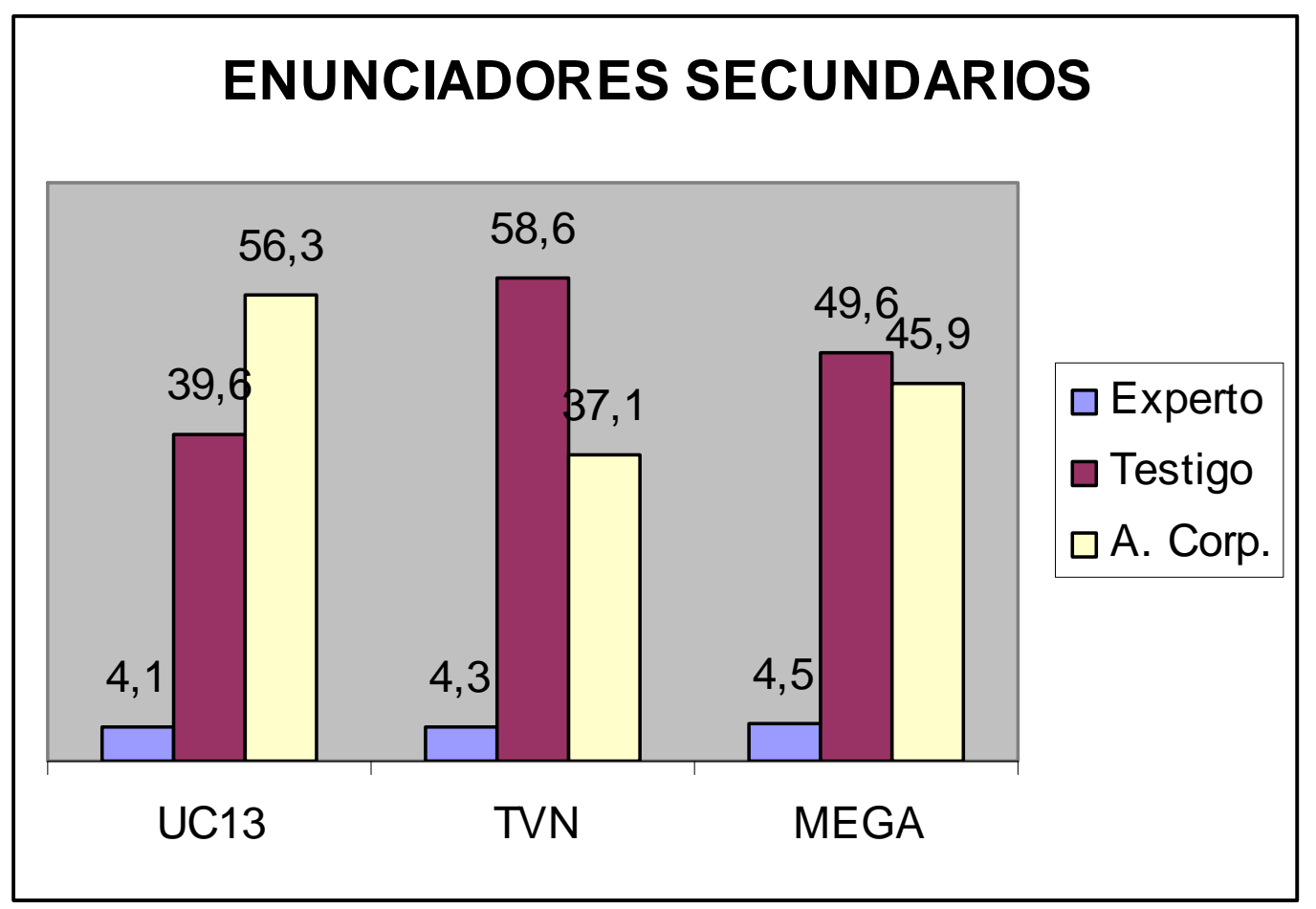

Figura 1: Enunciadores secundarios

Fuente: Elaboración propia en base a datos obtenidos en investigación CLACSO 2009

De esta manera, la disputa por la palabra oscila entre los testigos y los actores corporativos. Los tres canales privilegian la aparición y consulta a testigos. Las razones pueden ser muchas: (a) aparece en pantalla el ciudadano común y corriente lo que facilita la identificación con el telespectador; (b) los testigos, al dar sus propios testimonios, pueden explotar la dimensión emocional del relato o brindarle pinceladas de humor a lo que se presenta, es decir logran configurar relatos dramáticos y entretenidos y (c) ante la diversidad de opiniones que pueden aparecer el periodista siempre tiene la opción de encontrar alguna que pueda utilizar para reforzar su propio punto de vista, y por lo tanto construir las moralejas o brindar lecciones. Este último recurso narrativo es el que permite presentar un discurso "normalizador" al telespectador que opera como mecanismo de control social.

Es preciso recalcar aquí que nos referimos a las opciones del periodista más que a las imposiciones del canal, es decir a la autocensura, sin desconocer que en el trabajo periodístico también existen presiones silenciosas y censura propiamente tal. Al referirnos a la autocensura remarcamos dos tipos de procesos: el primero que se vincula con "las propias prácticas del reporteo y de construcción de la agenda noticiosa" (Cabalín \& Lagos, 2009, p. 57) y el segundo, a las rutinas periodísticas es decir "aquellas prácticas y formas de ejercicio marcadas por patrones, rutinizadas y repetidas que los trabajadores de los medios usan para realizar su trabajo" (Ramírez citando a Shoemaker y Resse, 1995).

En cuanto a los Actores Corporativos, los canales que más recurren a estos enunciadores son UC13 y MEGA, sin embargo el hecho de que aparezcan más tiempo en pantalla no 
se relaciona con el respaldo que se brinda a las instancias de poder (fundamentalmente al Estado) sino que aparecen con fuerza las instancias privadas que cuestionan a la autoridad. TVN por su parte no le da un mayor espacio a este tipo de enunciadores, pero claramente le da un respaldo al Estado al permitir que, en su puesta en escena, los actores corporativos representantes del poder estatal justifiquen o expliquen su accionar, muchas veces cuestionado por las demás emisoras.

En relación a cómo organiza y distribuye la palabra cada uno de los noticieros televisivos estudiados hemos podido observar que existen muchas coincidencias entre TVN y UC13 en lo que concierne al tipo de "enunciadores secundarios" 6 utilizados. Ambas emisoras privilegian a los actores corporativos por sobre los testigos, aunque, como ya hemos señalado, los objetivos o el rol que éstos cumplen al interior de la nota sea distinto en cada caso. MEGA, por su parte, privilegia fundamentalmente a los testigos, lo que hace que al hablar éstos desde sus propias sensaciones, sentimientos y vivencias, le dan al noticiero un tinte más emocional.

\subsection{Estrategias narrativas de implicación del telespectador}

Si bien los tres canales considerados utilizan los recursos narrativos de configuración de una intriga en las notas policiales, deportivas y las catástrofes; para las restantes notas existen diferencias.

UC13 es el que menos recurre a este tipo de estrategias (salvo en los temas nombrados), su estrategia de proximización ${ }^{7}$ está más centrada en la dimensión objetiva. Las notas presentadas tratan de ser neutras y el ordenamiento de los hechos es cronológico. Utiliza muy poco el recurso del suspenso y no usa elementos ficcionales en la presentación de los relatos. Esto le permite potenciar su rol crítico y racional. La gran mayoría de las "moralejas" son explícitas y formuladas mayoritariamente por Actores Corporativos. El periodista ancla no las enuncia en ningún caso. Esto refuerza la imagen de un noticiero neutro y objetivo que no agrega nada a la presentación de los acontecimientos, son los Actores Corporativos los que plantean las moralejas, lecciones o advertencias las que, en general, refuerzan la idea de la autonomía del telespectador, de su carácter crítico e independiente. Refuerzan la responsabilidad individual, los éxitos y fracasos dependen de cada uno. Si bien son valores cristianos también dan cuenta de una visión de mundo liberal.

TVN utiliza en mayor medida la estrategia narrativa y apela a la emoción. Trata de crear las instancias para el desarrollo de la empatía y la identificación con el otro, en el sentido de reafirmar la idea de comunidad. Es así que privilegia el relato de casos, humaniza a las personas, alivia el drama con la presentación de detalles graciosos o inesperados. Esto le permite desarrollar un punto de vista menos polémico y más

\footnotetext{
${ }^{6}$ Se refiere al discurso reportado no periodístico, es decir testigos, expertos y actores corporativos.

7 Entendida como una "minimización de la distancia, de la separación o de la diferencia" (Huynen, 1997, p. 183) y que como concepto tiene la ventaja de "connotar un cierto trabajo, un proceso, un tratamiento" (Fastrez \& Meyer, 1999, p. 149).
} 
optimista e integrador. En este noticiero se suele trabajar con moralejas implícitas y explícitas, éstas últimas a cargo fundamentalmente de Actores Corporativos y Testigos (enunciadores secundarios) y presentadores ancla. Da la impresión que en igualdad de condiciones, todos los que participan en el espacio público tienen la posibilidad de expresarse y que es posible aprender de cada una de las situaciones. A la base está la presunción de un telespectador con ideales democráticos, con un fuerte sentido de comunidad y de responsabilidad social, es decir de un "ciudadano" que participa de su entorno.

MEGA es el que más explota los recursos narrativos descritos. El manejo del suspenso, de la emoción, la utilización de elementos ficcionales, la música de fondo que no es utilizada por los otros dos canales, el recurso de explotar la imagen, los primeros planos de los testigos cuando lloran o cuando reclaman apelan fuertemente a la subjetividad y la emotividad. Presenta moralejas explícitas, enunciadas mayoritariamente por los profesionales del medio, es decir presentadores ancla y periodistas, seguidas por Testigos. Coherente con la imagen que MEGA está construyendo, los presentadores y periodistas son los encargados de "normalizar", de enseñar y advertir. Se presentan como los que saben y desde esa experticia asumen la labor de educar y guiar, asumiendo un rol de padre que guía y orienta. Se relacionan con un público ideal menos ilustrado, del que hay que hacerse cargo. Los valores dominantes son conservadores y cristianos.

La estrategia de proximidad desplegada por cada canal dice relación con los valores socio-culturales compartidos y puestos en evidencia: lo que parecen estar diciendo los canales es que están insertos en el espacio público y que cumplen un rol dentro de él, un rol de mediación comprometida, en el sentido de hacer extensivos los ideales y valores de la sociedad en la que se inscriben.

\subsection{El público - "ciudadano" de cada noticiero televisivo}

En este apartado reiteramos la pregunta por el lugar desde el cual habla el canal. La forma en que lo hace constituye lo que hemos denominado bisagra relacional pues por un lado distingue a cada emisora televisiva de su competencia y por otra, establece un tipo de vínculo específico y diferenciado con su telespectador ideal.

Cada canal, refleja una opción específica al situarse dentro del espacio público como un actor social que cumple un determinado papel. De esta manera plantea una relación interlocutiva que condiciona el papel que el telespectador debe asumir. Bajo la concepción de una democracia ampliada en la cual los medios actúan como intermediarios, todo aquel que accede al espacio informativo podría ser considerado un "ciudadano", a pesar de que en este caso se trataría de una ciudadanía pasiva donde no existe mucha posibilidad de diálogo y participación, pero se volverá sobre este punto más adelante. Entretanto se presentan las características enunciativas planteadas por cada canal y el tipo de "ciudadano" al que estarían apelando. 
Tabla 1: Resumen características enunciación

\begin{tabular}{|l|c|c|c|}
\hline Utilización discurso enunciadores & UC13 & TVN & MEGA \\
\hline Tipo de relato & Crítico & $\begin{array}{c}\text { Conciliador } \\
\text { Constructivo }\end{array}$ & $\begin{array}{c}\text { Instructivo } \\
\text { Cuestionador }\end{array}$ \\
\hline Público ideal & $\begin{array}{c}\text { Adulto } \\
\text { responsable }\end{array}$ & $\begin{array}{c}\text { Familiar } \\
\text { "Ciudadano" }\end{array}$ & $\begin{array}{c}\text { Infantil } \\
\text { Ingenuo }\end{array}$ \\
\hline Tipo de opinión construida & $\begin{array}{c}\text { Opinión } \\
\text { propia }\end{array}$ & $\begin{array}{c}\text { Opinión } \\
\text { compartida }\end{array}$ & $\begin{array}{c}\text { Opinión } \\
\text { sugerida }\end{array}$ \\
\hline
\end{tabular}

Fuente: Elaboración propia con datos investigaciones 2008 - 2009.

De acuerdo a lo que observamos, la postura de UC13 es la de plantearse como una entidad informativa independiente y seria, que utiliza el discurso reportado de los enunciadores secundarios como "pruebas" que validan su relato. Éstas intervenciones no aportan información nueva, solo respaldan y complementan la información que el canal va entregando.

(Periodista en off): Muchos de ellos aún no entienden la magnitud de la tragedia que impactó a otros de sus compañeros. Sólo disfrutan de esta bienvenida y se rinden ante el abrazo tan postergado de sus familiares

(Testigo): “Sabíamos que nuestras familias estaban preocupados por nosotros, pero no sabíamos nada"

GC: Conscripto Cristián Martínez, sobreviviente de la tragedia.

(Reencuentro conscriptos. UC13).

El punto de vista a partir del cual se estructura el relato es el crítico. UC13 se relaciona con un público ideal que podría ser adulto y maduro, que es capaz de formarse su propia opinión, que no desea sentirse manipulado y que quiere tener a la mano todos los antecedentes y la información más completa para poder tomar su propia decisión. El noticiero no toma partido explícito, trata de mantenerse a una distancia tal que le permita mirar el conjunto.

(Presentador ancla): Empezamos con las consecuencias que ha seguido teniendo el nuevo hecho de violencia ocurrido el fin de semana en el Barrio Suecia que terminó con un joven muerto y otros heridos. La policía ya maneja la identidad del supuesto autor de los disparos y al local de los hechos se le clausuró la patente de alcoholes. Informe de Enrique Barrera.

(Balacera Barrio Suecia, UC13)

TVN por su parte presenta dos puntos de interés: el público y la autoridad aunque en general está bastante más próximo a esta última y al respaldo de sus acciones al brindarle tribuna para dirigirse al público y presentar una postura bastante conciliadora entre ambos. Este canal es el que más potencia la lógica de "bisagra 
relacional", articula ambos discursos (pero desde el punto de vista de los Actores Corporativos) y los vincula con el telespectador (concebido como "ciudadano" propiamente tal, es decir como participante activo de la esfera pública democrática). Por otro lado, y al igual en el caso de UC13, los discursos reportados confirman lo que el canal va relatando.

(Periodista en off): Las tensas reuniones de último minuto para convencer a peruanos y bolivianos de que no forzaran una votación, fracasaron.

(Actor Corporativo): "Razones históricas nos impiden sumarnos hoy a la eventual mayoría que ha surgido en torno a la candidatura a la Secretaría General de nuestra organización del señor José Miguel Insulza.

GC. Juan Ignacio Siles, Canciller de Bolivia (Insulza Secretario General OEA, TVN).

El punto de vista a partir del cual estructura el relato es conciliador. TVN se relaciona con un público ideal que podría ser el participante en las decisiones que toma la autoridad que él mismo ha elegido, que se entrega al ejercicio democrático donde el diálogo es el instrumento y el que, a pesar de las diferencias que existan entre los distintos actores, está por el consenso. El noticiero asume a veces el rol crítico, cuestionando y exigiendo a la autoridad respuestas pero siempre en un plano constructivo, en una crítica que ayuda a reflexionar y así lo plantea al telespectador. Esta mirando el proceso democrático como participante activo de él.

(Actor Corporativo): Es una gran oportunidad para ellas, es una nueva vida aquí en este lugar, yo esta mañana estuve con ellas a las 10 de la mañana y nos tomamos un cafecito juntas. ¿Cómo está usted? (la ministra hace una pausa para saludar con un beso a un niño que se le acerca) Para ellas esta es la gran oportunidad y ella hizo la tarea

GC: PATRICIA POBLETE, MINISTRA DE VIVIENDA

(La ministra se ve con cara de satisfacción y empatía, en tanto Patricia, está a su lado con la cara llena de lágrimas por la emoción)

(Toma de Peñalolén. TVN)

MEGA se plantea como cercano al telespectador, en todas sus notas se dirige a su público, habla a través de él, cuestiona a la autoridad, exige respuestas en nombre de aquellos a los que está representando. Pero a su vez los instruye y les explica lo que está ocurriendo, les indica cómo deben reaccionar y qué deben pensar de los distintos acontecimientos que se presentan. Los enunciadores secundarios (en su mayor parte testigos) presentan discursos altamente redundantes, que no brindan información que el canal no haya ya entregado. Aportan por lo tanto la "prueba" de las demandas que se realizan y la emocionalidad con la que debe ser "leído" el relato informativo. 
(Periodista en off): Todo fue desconcierto. Las víctimas quedaron tendidas en plena calle.

(Testigo): “Es terrible ver a una persona que se te va en tus manos, porque yo le tomaba la cabeza y se estaba desangrando, se fue muriendo de a poco y se fue muerto de acá"

GC: Ingrid, auxilió a los heridos

(Balacera Barrio Suecia. MEGA)

El punto de vista a partir del cual estructura su relato es el comprometido con su público. MEGA se relaciona con un público ideal carente de voz, de espacios donde expresar su opinión, es decir un público "infantil" o "ingenuo" que se encuentra fuera de los círculos de poder o de decisión y al que hay que apoyar, representar y respaldar. $\mathrm{Su}$ discurso es crítico y cuestionador de la autoridad, pareciera que no confía mucho en las decisiones que la autoridad toma, se plantea más bien como opuesto al Gobierno.

(Testigo 1): que esto no quede impune, que los delincuentes, que son menores de edad de 17 años de 15 años, paguen por este delito, que la pena de muerte, no pido pena de muerte, pido la pena máxima, que se puede conceder.

GC: Jessica Fuenzalida. Esposa de carabinero baleado.

(Periodista en off): Una pena que sirva de ejemplo por la muerte de un carabinero, que se suma a los mártires de la institución.

(Muerte carabinero en Curicó. MEGA).

Cada noticiero televisivo se vincula con su público a partir de estrategias narrativas que lo distinguen de los demás. Los relatos presentados son coherentes con la imagen que proyecta el presentador ancla en cada uno de los casos. Un breve análisis ${ }^{8}$ de su vestuario, postura y enunciación permite reconocer el tipo de telespectador, y por tanto de "ciudadano" que cada uno de los noticieros está construyendo.

En el caso de UC13 el espacio del noticiero se configura como un espacio profesional, como un trabajo. Las notas presentadas son tratadas con seriedad y cuidado, de la manera más neutra posible. La invitación al telespectador ideal es a recibirlas como tal, con responsabilidad, dejándole la opción de formarse su propia opinión. Con un presentador ancla serio, profesional, controlado en sus reacciones, con una gestualidad mínima en un espacio de trabajo moderno, que presenta notas que son tal cual él se presenta. Utilizando muy pocos adjetivos, tratando de regirse por la estructura informativa clásica aunque, desarrollando una intriga, el punto de vista es crítico y cuestionador. Sus juicios están avalados y reforzados por otros enunciadores. Es un discurso controlado y dominado. A la base se puede reconocer como principio de organización del relato propuesto, la idea de un individuo que debe hacerse responsable por sus actos.

\footnotetext{
${ }^{8}$ Los presentadores ancla son analizados en el periodo 2005 - 2008. En el 2009 se producen algunos cambios que no están consignados en este artículo.
} 
En TVN una jovial pareja da la bienvenida, cercanos a su público, sonrientes, humanos... se conmueven, se sorprenden. Da la impresión de encontrarse en familia, en una familia en que se pueden conversar las cosas, no asumen un rol de padres sino de amigos y la visión de país es como la de una casa, con problemas que hay que solucionar pero cuyo espíritu es tratar de hacer las cosas bien. Invitan a los telespectadores ideales a formar parte de esta familia ciudadana y a enfrentar en conjunto los problemas. Se instala la idea de comunidad y ciudadanía. Utilizan adjetivos para introducir notas que, salvo en el tema deportivo, son bastante más positivas que en el caso anterior, notas que sutilmente apoyan el quehacer de autoridades o les brindan la plataforma para explicar los hechos. Generalizan bastante, ya no es sólo el individuo el afectado, el protagonista es la sociedad, es el país. Por tanto sus notas intentan representar al común de los chilenos, a la gran mayoría. Quizás es esta particularidad la que lo distingue de UC13, quien podría estar prefigurando como público objetivo a un individuo de elite, independiente y crítico, mientras que TVN trataría de llegar a un individuo más concebido como parte de una sociedad y con una vinculación positiva con sus autoridades.

En MEGA, ni tan profesionales ni tan amistosos, los presentadores asumen un rol paternal o maternal según sea el caso. Enseñan a su telespectador la forma en que hay que dotar de sentido al acontecimiento que se presenta, indican cómo hay que reaccionar, cuestionan y critican en su nombre, dando por supuesto que "representan" o que "hablan por" su telespectador, por sus hijos en sentido figurado. El papel es didáctico y ejemplificador. Los presentadores son formales y clásicos, muy parecidos al estilo de presentador de UC13. La presentadora ancla es más emotiva y puede ser cercana a su público. Utiliza adjetivos que permiten leer la nota con los énfasis construidos por el canal. Las notas presentadas utilizan muchos más recursos ficcionales que en los dos canales ya mencionados: música, imagen sin voz, recreaciones en algunos casos y relatos en off melodramáticos. Explotan los relatos de casos y sus fuentes son mayoritariamente testigos, que hablan desde su propia emoción. Las notas son redundantes y simples en su composición y los personajes pueden ser fácilmente ordenados en algún polo (bueno-malo).

\section{CONCLUSIONES}

Al ser el noticiero televisivo la nueva plaza pública donde se dan cita los distintos actores de la esfera social, éste se transforma en el espacio de reunión privilegiado pues los invitados son seleccionados por los profesionales del medio. Cualquiera puede atisbar por la ventana pero son pocos los que están dentro del salón. En ese sentido estamos frente a un simulacro de participación por lo cual, quienes en realidad tienen el poder de otorgar la palabra son los profesionales del medio: periodistas.

Esto implica una selección de voces y por tanto una opción narrativa. ¿Desde donde habla cada noticiero? Desde el espacio que permite una mayor identificación de sus audiencias, desde el lugar que asume la instancia productora. En la gran mayoría de 
los casos el noticiero actúa como un representante, invistiéndose con el poder que, en sentido figurado, le otorga la audiencia al elegirlo como fuente de información.

El noticiero televisivo asumiría entonces un rol de mediación comprometida, en el sentido de que la forma de construir el relato informativo y de articular las distintas voces de la esfera pública implican una opción. No se habla desde una plataforma neutra, se reconoce una intención y un sentido.

Desde la enunciación del noticiero se reconocen distintos tipos de actores, destacándose los testigos, aquellos que hablan desde sí mismos pues por un lado, facilitan la identificación del telespectador y por otro, imponen una cuota de emoción a la nota.

Todo lo que ese telespectador piensa sobre sus autoridades, sus reclamos, sus molestias, lo ve desfilar en la pantalla y participa en un simulacro de democracia. No hay necesariamente una perversión del sistema informativo, el medio no manipula al telespectador: a priori no se podría hablar de una mala intención porque hay mecanismos, en algunos casos inocentes, que operan en el aparataje productivo: más que censuras y restricciones explícitas hacia el quehacer periodístico los profesionales del medio se enfrentan a la autocensura o a la interiorización de rutinas que, al serializar la producción de la información (es decir, al copiar el molde) dejan de preguntarse por la naturaleza de los relatos que construyen. $Y$ esto no es como una mala historia, es más bien el recuento de lo que ocurre en el espacio social del que un telespectador es parte y al que no tiene acceso directo. Es decir, donde no puede contrastar la información (Antezana, 2010).

A nivel general las notas que más dejan en evidencia el punto de vista de cada canal y a quién se está dirigiendo son las notas policiales y sociales, aunque también es posible observar estos distintos énfasis en otro tipo de notas.

Como los noticieros no pueden hablar a la sociedad, pues ésta es una sustantividad imaginaria, lo hacen a la forma objetiva que toma: el espacio público. Este, por su parte, debe materializar el encuentro entre vida cotidiana y modernización, por medio de relatos normalizadores, que gracias a sus estrategias de verosimilitud y efectos de realidad, proveen a los espectadores de un régimen de significación permanente que vuelve interpretables los acontecimientos. Estos relatos organizadores del mundo, ya hemos visto que no pueden ser "objetivos", se organizan bajo una cierta lógica, fundamentalmente narrativa, pero con matices relacionados con los distintos tipos de propietarios de medios y la relación que éstos instauran con instancias de autoridad.

El espacio público al que hacen referencia los noticieros entonces sería aquella articulación simbólica donde las diversas narrativas modernas se excluyen y fusionan sin tregua. De esta forma el concepto de espacio público que se deduce, es un espacio contemporáneo, más plástico y transversal, con diferenciaciones instrumentales, tendientes a la continua apelación a públicos heterogéneos. El noticiero, aparece como el medio privilegiado para la formación de una identidad colectiva, caracterizando al 
"chileno" medio, canalizando sus principales temores y preocupaciones; su miedo a lo extraño o extranjero, su noción de país. Cada canal al definir su público ideal, refuerza las características que cree permitirán que éste se identifique y relacione con la propuesta discursiva que se le entrega, pero también lo invita a participar del juego democrático en un espacio en que no puede negociar su participación.

No habría, necesariamente, un paso de lo público a lo privado, sino una reconfiguración del uso discursivo de la representación. Los sujetos buscarían mostrarse y reflejarse por medio de la instancia que mejor garantice su reconocimiento. La emoción no puede ser reducida a la sola esfera privada sino que se vive colectivamente. La emoción viste la intriga, viste la noticia presentada. El noticiero no sólo nos da a conocer el acontecimiento sino que nos hace sentir próximos a él, nos hace tomar una posición, nos hace vivirlo y revivirlo una y otra vez.

El espacio del noticiero se constituiría en un espacio de debate de intereses públicos y privados y de constitución de la opinión, sin embargo y tal cual lo hemos visto en el análisis de los noticieros realizado, éste debate responde a lógicas organizativas distintas: (1) en el caso de UC13 se trataría más bien de un espacio que hace referencia a las garantías, responsabilidades y derechos de particulares (empresas o individuos) que participan del sistema productivo; es decir más que a ciudadanos se estaría apelando a consumidores; (2) para TVN en cambio, el espacio del noticiero convoca, invita y hace partícipes a todos aquellos actores de un espacio público concebido como el lugar de la participación ciudadana. Cada uno de los actores sociales involucrados tienen un lugar, forman parte de una ciudadanía, fiscalizan y controlan a las autoridades que han elegido pero, son junto con ellas responsables de lo que ocurre en esa esfera pública, y (3) MEGA replica la vieja idea de un Estado paternalista y protector, que debe hacerse cargo y tomar decisiones que velen por las mejores condiciones de vida de sus "hijos". Estos son concebidos como dependientes y beneficiarios, no manejan toda la información y esperan que los problemas sean resueltos por otros.

Y en relación a la opinión que se supone constituyen, ésta también está diferenciada pues UC13 estaría propiciando la formación de una "opinión propia”, mientras que TVN trabajaría más bien la idea de una "opinión compartida", y MEGA la de una "opinión sugerida".

\section{REFERENCIAS}

Antezana, L. (2008). Estrategias de proximización del noticiero televisivo chileno para vincularse con su público. Bélgica: Tesis Doctoral. Universidad Católica de Lovaina.

Antezana, L. (2010). El noticiero televisivo chileno: bisagra relacional entre Estado y Clases Sociales en el espacio democrático. Informe Final. Beca de Investigación CLACSO- ASDI 2008-2009. 
Arcos, C. (2010). La mirada de Chilevisión en las tres últimas Clasificaciones Mundialistas. Memoria para obtener el Título de Periodista. Santiago de Chile: Universidad de Chile.

Bauman, Z. (2008). La globalización. Consecuencias humanas. Buenos Aires: Fondo de Cultura Económica.

Cabalín, C. \& Lagos, C. (2009). Libertad de expresión y periodismo en Chile: presiones y mordazas en Palabra Clave, Vol. 12, número 1. Bogotá: Universidad de La Sabana.

Charaudeau, P. (2005). Les médias et l'information. L'impossible transparente du discours. De Boeck \& Larcier s.a. Institut nacional de l'audiovisuel. Bruselas: Éditions De Boeck Université.

Echeverría, B. (2000). La modernidad de lo barroco. México: Universidad Autónoma de México.

Fastrez, P. \& Meyer, S. (1999). Télévision locale et proximité en Recherches en Communication. Un demi-siécle d'études en communication. $\mathrm{n}^{\mathrm{o}}$ 11. Paris: Presses Universitaires du Mirail.

Ferry, J. M. (1989). Las transformaciones de la publicidad política en El Nuevo Espacio Publico. J.-M. Ferry, Dominique Wolton et al. (Eds.) Barcelona: Editorial Gedisa.

Haber, S. (2001). Jürgen Habermas Une Introduction. París: Agora. Collection dirigée par Francois Laurent. Pocket/La découverte.

Huynen, C. (1997). La proximité dans l'esprit du temps, en Recherches en Communication. Le récit mediatique, (7). Paris: Presses Universitaires du Mirail.

Lagos, C. (2009). El aborto en los medios de comunicación: El evangelio según MEGA en Nación golpeadora. Manifestaciones y latencias de la violencia machista. Santiago de Chile: Red Chilena contra la violencia doméstica y sexual.

Lechner, N. (2005). Obras Escogidas. Santiago de Chile: Ediciones LOM.

Ramírez, P. (1995). Rutinas periodísticas en los medios chilenos: una transición incompleta en Cuadernos de Información, n 10. Santiago de Chile: Universidad Católica de Chile.

Soulages, J.-C. (1999). Les mises en scène visuelles de l'information. Etude comparée France, Espagne, Etats-Unis. Collection Médias - Recherches. París: NATHAN.

Wolton, D. (1989). Los medios, eslabón débil de la comunicación política en El Nuevo Espacio Público. Barcelona: Editorial Gedisa. 
Wolton, D. (1992). Les contradictions de l'espace public médiatisé. París: Hermès 10.

\section{Lorena Antezana-Barrios}

Doctora en Información y Comunicación (U. Lovaina-La-Nueva, Bélgica), Magíster en Comunicación Social (Universidad de Chile), Diplomada en periodismo cultural y Crítica Especializada (U. de Chile), Licenciada en Comunicación Social (Periodismo) (U. de Chile). Coordinadora de Proyectos. Directora de Desarrollo en la Fundación Educacional y Cultural San Pablo. Formuladora, implantadora, seguidora, monitora y evaluadora de proyectos sociales. Experta en selección y conformación de equipos y en coordinación técnica como monitora/formadora. 